九州大学学術情報リポジトリ

Kyushu University Institutional Repository

\title{
Maturity and Freshness Evaluation of Japanese Apricots by Means of Delayed Light Emission
}

Chuma, Yutaka

Laboratory of Agricultural Process Engineering, Faculty of Agriculture, Kyushu University

Nakaji, Ke i

University Farm, Faculty of Agriculture, Kyushu University

Ohura, Masanobu

Laboratory of Agricultural Process Engineering, Faculty of Agriculture, Kyushu University

https://doi.org/10.5109/23755

出版情報: 九州大学大学院農学研究院紀要. 27 (1/2)，pp.21-31，1982-10. Kyushu University バージョン：

権利関係 : 


\title{
Maturity and Freshness Evaluation of Japanese Apricots by Means of Delayed Light Emission
}

\author{
Yutaka Chuma \\ Laboratory of Agricultural Process Engineering, Faculty of \\ Agriculture, Kyushu University 46-05, Fukuoka 812 \\ Kei Nakaji \\ University Farm, Faculty of Agriculture, Kyushu \\ University, Kasuya-Cho, Fukuoka, 811-23 \\ Masanobu Ohura \\ Laboratory of Agricultural Process Engineering, Faculty of \\ Agriculture, Kyushu University 46-05, Fukuoka 812
}

(Received March 30, 1982)

\begin{abstract}
Fundamental characteristics of delayed light emission (DLE) of Japanese apricots were investigated to evaluate the maturity and freshness. For obtaining high DLE intensity, dark period longer than $20 \mathrm{~min}$, exciting illuminance higher than $5,500 \mathrm{Ix}$, exciting time for one $\mathrm{sec}$ and decay period for $1.5 \mathrm{sec}$ are recommended. After harvest, there was high correlation between the peel color and DLE, and between hardness of fruits and DLE. Low temperature storage for a short period of time is effective for maintaining the freshness of the fruits, and the change of peel color and hardness during the storage was evaluated by means of DLE.
\end{abstract}

\section{INTRODUCTION}

The production of Japanese apricots was 57,000 tons in 1976. The demand for this product is increasing due to its use as a raw material in making plum liquor and pickled plums. Unripened green fresh fruits are used to manufacture plum liquor while slightly ripened fruits are used for pickling.

Japanese apricots have a unique ripening pattern which presents a problem to commercial processors. Apricots tend to ripen quickly and soften easily after harvesting. Consequently the processing season is very short. Two areas of research are particularly pertinent at this time: (1) to investigate methods for maintaining freshness, and (2) to develop equipment for automatically sorting apricots according to maturity and/or quality.

The authors have investigated the delayed light emission (DLE) characteristics of tomatoes, Satsuma oranges, green-tea leaves, persimmons, and bananas and have demonstrated the applicability of DLE for nondestructively evaluating maturity and quality of these products. This paper describes the relationship between DLE and certain quality factors of Japanese apricots as related to automatic sorting. 


\section{MATERIALS AND EQUIPMENT}

\section{Materials}

Samples of apricots (Prunus mume Sieb. et Zucc., Nanko) were collected at random from three trees during the period from the end of May to the beginning of June, 1978. All samples were harvested around 11:00 am and tested two hours later.

\section{Measurement of DLE}

The apparatus for measuring DLE was similar to that reported previously (Chuma and Nakaji, 1976). For most of the work reported here, DLE measurements were taken from a $491 \mathrm{~mm}^{2}$ area on the cheek of the apricots. This area was reduced to $398 \mathrm{~mm}^{2}$ for the tests to determine optimum harvest time and storage conditions.

\section{Peel color}

Peel color of the apricots was determined by visually comparing each fruit with a color chart in the Japan Industrial Standard, JIS Z 8721. Color was expressed as a function of the Munsell renotation system.

\section{Hardness}

A reduction of fruit hardness is generally regarded as an index of increasing maturity. A universal testing machine (Shinkoh Model TOM 10000X) was used to measure fruit hardness. Each fruit was compressed by a steel plate driven at a constant speed of $15 \mathrm{~mm} / \mathrm{min}$ up to $5 \mathrm{kgf}$. Hardness was expressed as a ratio of force to deformation of the fruit pressed by the flat plate $(\mathrm{kgf} / \mathrm{mm})$.

\section{Acid content}

The acid content of the apricots was determined by a titration method as follows. Five grams of flesh including the peel were ground in $20 \mathrm{ml}$ of distilled water in a Warring blender. The mixture was diluted with $25 \mathrm{ml}$ of distilled water and placed in a centrifuge for separating the pulp from the liquid. Two $\mathrm{ml}$ of the supernatant liquid was diluted 10 times with distilled water, a drop of phenolphthalein was added, and the total solution was neutralized with $0.1 \mathrm{~N}$ natrium hydroxide. The acid content (AC) was expressed as:

$$
A C=\frac{(7.005)(V)(v)}{10^{4}} \quad(\%),
$$

where $V$ is the volume of supernatant liquid (ml), $v$ is the volume of $0.1 \mathrm{~N}$ natrium hydroxide $(\mathrm{ml})$, and 7.005 is the weight of citric acid $(\mathrm{mg})$ that can be neutralized by $1.0 \mathrm{ml}$ of $0.1 \mathrm{~N}$ natrium hydroxide. 


\section{RESULTS AND DISCUSSION}

\section{Fundamental characteristics of DLE}

(1) Effect of dark period

The authors found that extending the dark period just before excitation would increase the DLE intensity. This phenomenon, referred to as "dark recovery", has been observed for tomatoes, Satsuma oranges, persimmons and bananas (Chuma and Nakaji, 1980). The effect of this dark period on DLE of apricots was investigated for a pre-illumination time of $60 \mathrm{sec}$, an excitation intensity of 5,500 Ix and an excitation time of 2 sec.

Fig. 1 shows the relationship between the dark period and DLE intensity for various decay periods. DLE was found to decrease for dark period shorter than one minute, but was found to increase for dark periods greater than one minute. DLE reached its maximum for a minimum dark period of $20 \mathrm{~min}$ and a maximum decay time of 1.5 sec. The dip in the curves at one minute dark period was observed for the dark recovery of persimmons excited with 1,750 Ix (Chuma et al., 1982). For a given decay period, DLE for apricots (as seen in Fig. 1) increased very little for dark periods in excess of $20 \mathrm{~min}$.

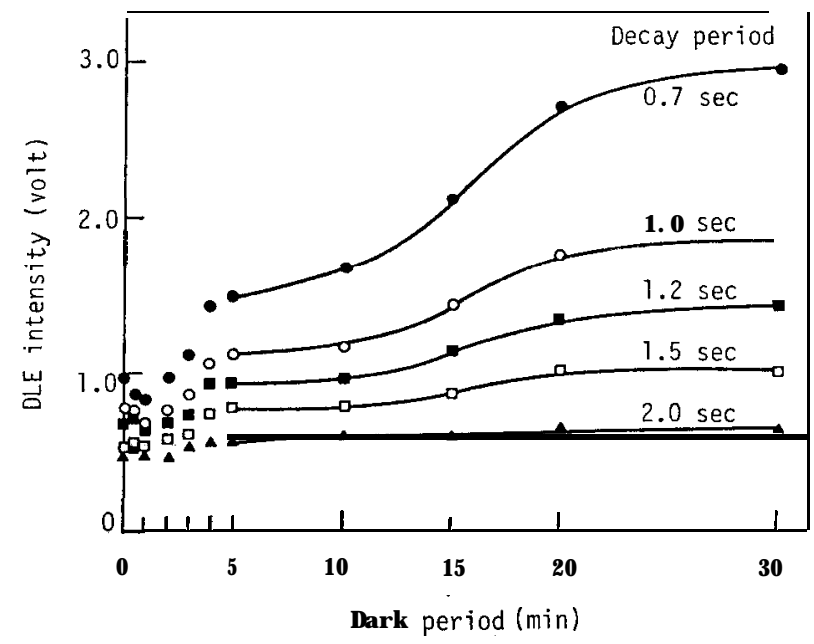

Fig. 1. Effect of dark period on DLE intensity. Conditions for determination of DLE: $60 \mathrm{sec}$ pre-illumination time, 2 sec exciting time, 5,500 $\mathrm{lx}$ illuminance, and $24.0^{\circ} \mathrm{C}$ fruit temperature.

(2) Effect of exciting time on DLE

As shown in Fig. 2, DLE is drastically affected by the length of 5,500 Ix excitation. DLE intensity reaches maximum value for an excitation time of 1.0 sec. Longer excitation times caused DLE degradation; little change in DLE occurs for excitation times in excess of 60 sec. An excitation time of 


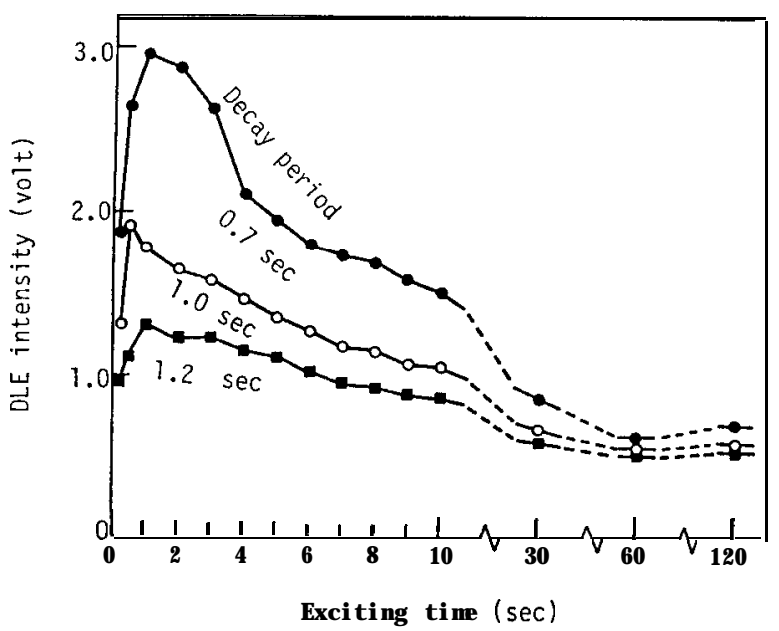

Fig. 2. Effect of exciting time on DLE intensity. Conditions for determination of DLE: 10 min dark period, 5,500 Ix illuminance, and $25.8^{\circ} \mathrm{C}$ fruit temperature.

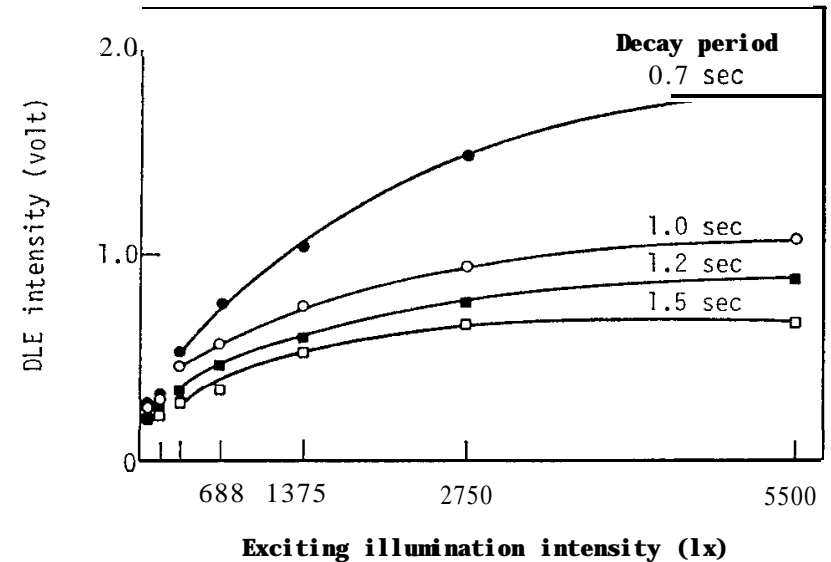

Fig. 3. Effect of exciting illumination intensity on DLF intensity. Conditions for determination of DLE: $10 \mathrm{~min}$ dark period, $2 \mathrm{sec}$ exciting time, and $25.5^{\circ} \mathrm{C}$ fruit temperature

$2.0 \mathrm{sec}$ was considered the optimum excitation time for further studies.

(3) Effect of illuminance on DLE

The effects of excitation intensity on DLE are shown in Fig. 3. Excitation intensity was expressed as illuminance $(I x)$ at the surface of the apricot. As seen in Fig. 3, 2,750 Ix caused DLE saturation for a $1.5 \mathrm{sec}$ decay period, but $5,500 \mathrm{Ix}$ did not reach saturation with a $0.7 \mathrm{sec}$ decay period. The information in Fig. 3 is very useful when considering the matter of lamp stability. 
It is shown here that if high intensity lamps are used (viz. 5,500 lx) lamp stability is not a problem because DLE saturation is easily achieved. Therefore, further tests 'were performed with a lamp having an illuminance of $5,500 \mathrm{~lx}$.

\section{(4) Effect of temperature on DLE}

The fruit temperatures in Fig. 4 were the average of two thermocouple readings with the thermocouples inserted into the fruit $1.0 \mathrm{~mm}$ below the surface. DLE was observed to reach a maximum at about $24^{\circ} \mathrm{C}$ for decay periods of 0.7 and $1.0 \mathrm{sec}$. For the decay period of $1.2 \mathrm{sec}$, DLE remained essentially constant over the temperature range from 23 to $28^{\circ} \mathrm{C}$.

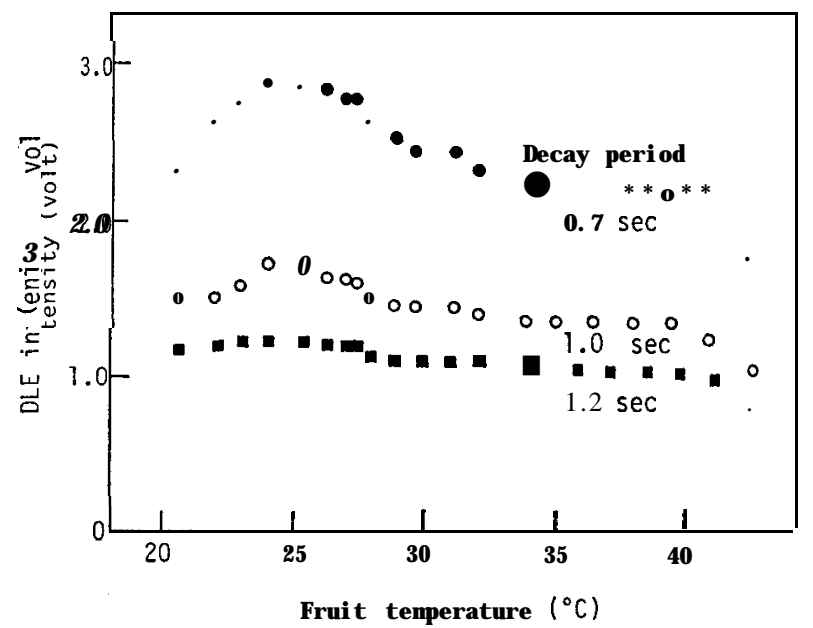

Fig. 4. Effect of fruit temperature on DLE intensity. Conditions for determination of DLE: 4.5-5.7 min dark period, 2 sec exciting time, and $5,5001 \mathrm{x}$ illuminance.

\section{DLE as a function of harvest date and duration of storage}

\section{(I) Q uality of apricots as a function of harvest date}

The optimum harvest season for apricots in Fukuoka is usually from the end of May to the middle of June. DLE intensity, peel color, hardness, and acid content were measured every day from June 7 to June 16, 1978.

The results of these tests are shown by the solid lines in Fig. 5. The DLE data points are the average of 10 readings along with the $95 \%$ confidence limits. The DLE of harvested fruits did not significantly change during the test period.

Hardness and acid content changed very little during the test period. The mean value of hardness and acidity was $10.9 \mathrm{kgf} / \mathrm{mm}$ and $4.75 \%$ respectively. Peel color, another quality factor, did not change during this period and was found to have a Munsell hue of 5GY 7/6 (JIS Z 8721). 


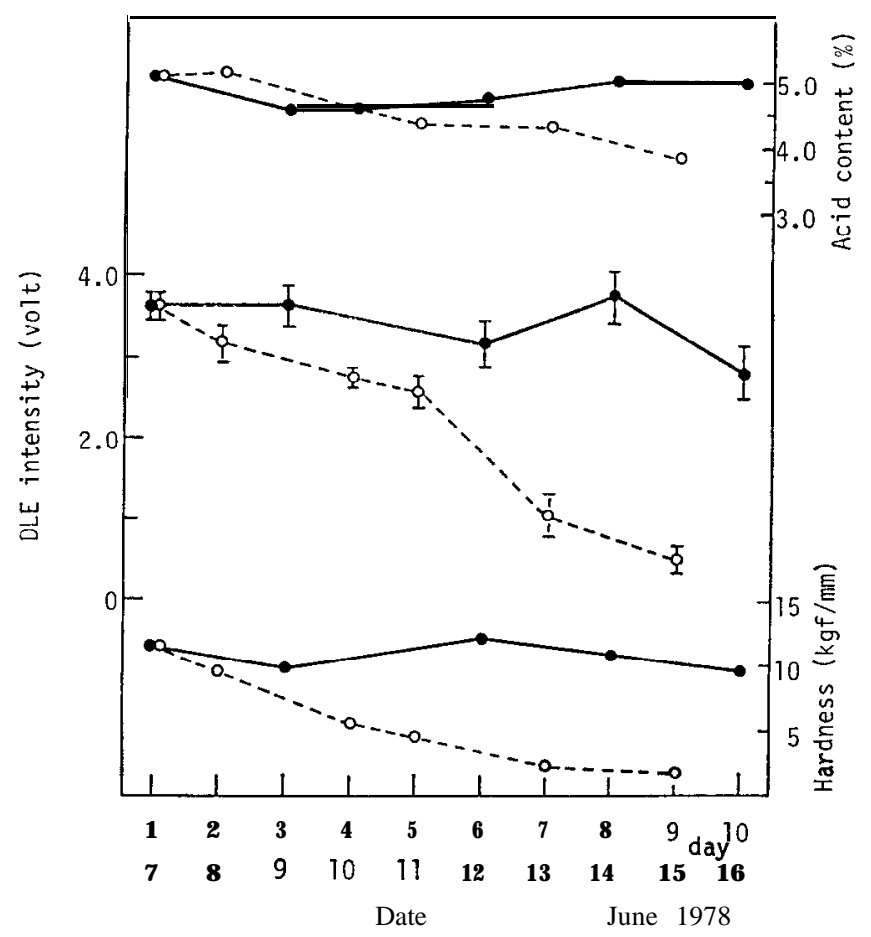

Fig. 5. Change of DLE intensity, acid content and hardness in Japanese apricots. Conditions for determination of DLE: $10 \mathrm{~min}$ dark period, 2 sec exciting time, 5,500 Ix illuminance, $0.7 \mathrm{sec}$ decay period, and $3.98 \mathrm{~cm}^{2}$ illumination area on Japanese apricots. - : harvest; o: storage. Vertical lines: 95 percent confidence interval.

(2) Relationship between DLE and quality factors of apricots during storage

Harvested apricots ripen and soften quickly when kept at room temperature. Samples were harvested on June 7 and stored at room temperature $\left(22.5\right.$ to $\left.26.5^{\circ} \mathrm{C}\right)$. DLE intensity, peel color, hardness, and the acid content of 10 fruits were measured every day for 9 days. The results are shown in Fig. 5 by the dotted lines.

The color/appearance of the fruit changed very little during the first 4 days of storage (Munsell hue 5GY 7/6). By the 7th day the fruits were yellow (10Y to $7.5 \mathrm{Y}$ ) and by the 9th day they were yellow-ripe (5Y to $2.5 \mathrm{Y}$ ) with small brown dots on the surface.

DLE was $3.6 \mathrm{~V}$ on the first day and gradually decreased to $2.5 \mathrm{~V}$ on the 5th day. DLE dropped much faster from day 5 to day 9 with a final DLE value of approximately $0.5 \mathrm{~V}$. The data shows that DLE is more sensitive to maturity changes than the human eye.

Hardness changed in comparatively the same manner as peel color and DLE. Hardness decreased gradually from $11.5 \mathrm{kgf} / \mathrm{mm}$ on the first day to 2.3 $\mathrm{kgf} / \mathrm{mm}$ on the 7 th day. Acidity dropped gradually from $5 \%$ to $3.9 \%$ during 
the same period.

Iwata and Ogata (1976) investigated the respiration and ethylene production of apricots during the ripening stage and reported that apricots exhibit a climacteric rise in ethylene similar to that observed in bananas and pears. Neither the respiration rate nor ethylene production was measured, but softening of the flesh and rapid peel color changes, usually associated with a climacteric rise in respiration and ethylene production, was observed. Japanese apricots appear to reach the climacteric stage on the 4th or 5th day after harvest when stored at room temperature.

\section{(3) Relationship between peel color and DLE}

The three Munsell criteria (hue, value and chroma) were observed but the change in value and chroma was so little that those data will not be presented. Only hue will be discussed. Fig. 6 shows the relationship of DLE to fruits harvested on June 7th and 16th and then stored at room temperature. Measurements of hue and DLE were made daily. As hue changed from 5GY to $2.5 \mathrm{Y}$ the DLE decreased from $2.9 \mathrm{~V}$ to $0.2 \mathrm{~V}$. The ease with which DLE measurements are made and the high sensitivity of DLE to pigment changes makes DLE preferable to color measurements.

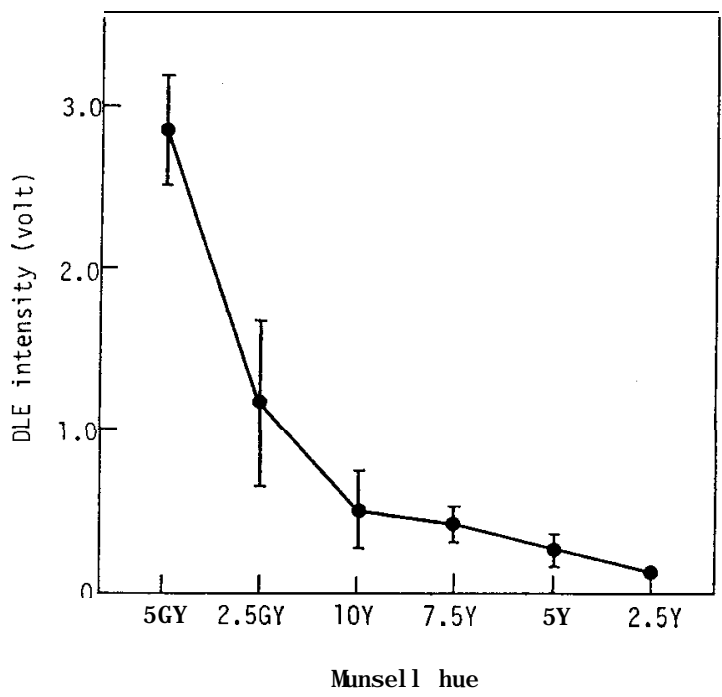

Fig. 6. Relationship between hue of peel color and DLE intensity of Japanese apricots. Conditions for determination of DLE: $10 \mathrm{~min}$ dark period, 2 sec exciting time, 5,500 1x illuminance, 0.7 sec decay period, $22.8-28.5^{\circ} \mathrm{C}$ fruit temperature, and $3.98 \mathrm{~cm}^{2}$ illumination area on Japanese apricots. Vertical lines: 95 percent confidence interval.

\section{(4) Relationship between hardness and DLE}

The relationship between hardness of apricots stored at room temperature and DLE is shown in Fig. 7 (filled circle). A linear equation was fitted 


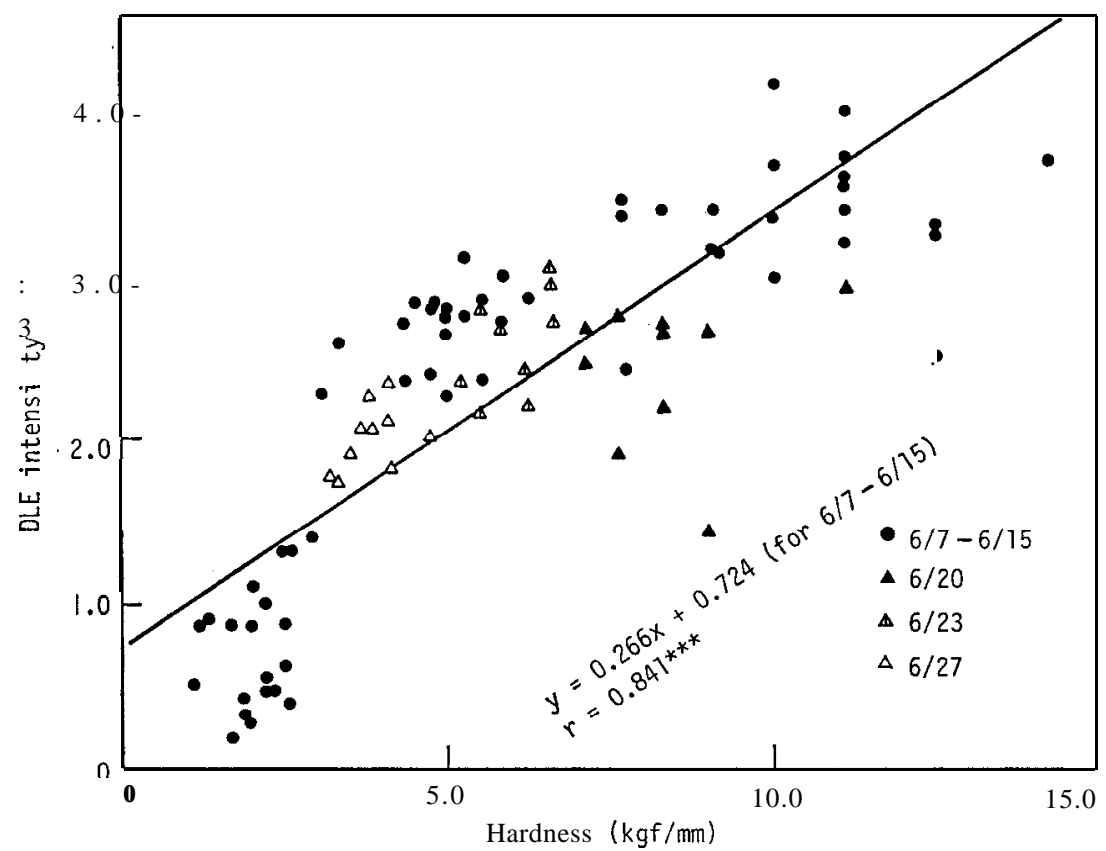

Fig. I. Relationship between hardness and DLE intensity of Japanese apricots after harvest. Conditions for determination of DLE were the same as in Fig. 5. were measured on the harvested day of $6 / 7$ to $6 / 15 ; \mathrm{A}, \mathbf{A}$, and $\triangle$ were harvested on $6 / 16$ and stored at low temperature of $10^{\circ} \mathrm{C}$, and measured on $6 / 20,6 / 23$, and $6 / 27$, respectively. $* * *$ indicates statistical significance at 0.1 percent level.

to the data and is expressed as

$$
y=0.266 x+0.724
$$

where $\mathrm{x}$ is hardness ( $\mathrm{kgf} / \mathrm{mm})$ and $y$ is DLE intensity (V) for a decay period of $0.7 \mathrm{sec}$. The correlation coefficient was 0.841 at the 0.1 percent level of significance. The data indicates that hardness, one of the best indicators of freshness, can be estimated by DLE measurements.

\section{Change of DLE intensity during storage}

It is known that storing apricots under low temperatures suppresses ripening and retains the freshness of the product (I wata and Ogata, 1976), but the optimum storage conditions of temperature and relative humidity have not been established. In order to establish these conditions, the change of quality factors (hardness and acidity) and DLE were measured under the following conditions :

(1) Room temperature (24 to $28^{\circ} \mathrm{C}$ ), not packed, control.

(2) Room temperature $\left(24\right.$ to $\left.28^{\circ} \mathrm{C}\right)$, packed in polyethylene film $(0.03 \mathrm{~mm})$.

(3) Low temperature $\left(10^{\circ} \mathrm{C}\right)$. not packed. 


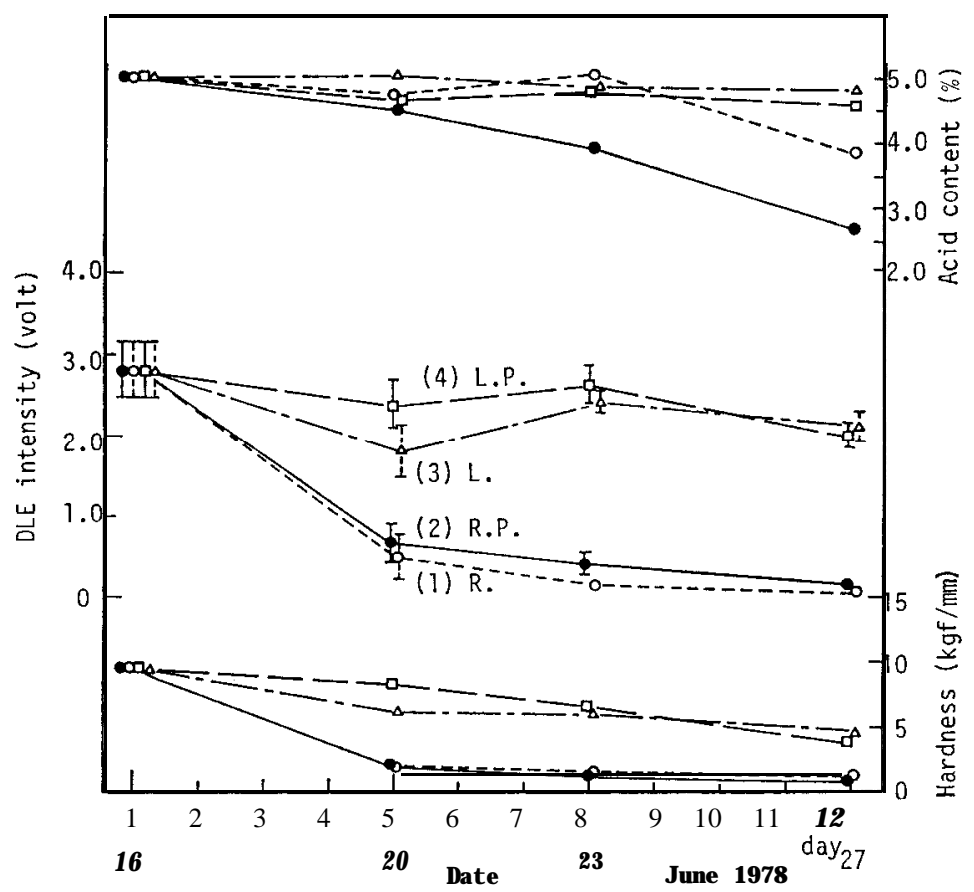

Fig. 8. Change of DLE intensity, acid content and hardness in Japanese apricots during the storage at various conditions. Conditions for determination of DLE were the same as in Fig. 5. (1) : room temperature, non packed; (2): room temperature, packed with polyethylene film; (3): low temperature $\left(10^{\circ} \mathrm{C}\right)$, non packed; (4) : low temperature $\left(10^{\circ} \mathrm{C}\right)$, packed with polyethylene film. Vertical lines: 95 percent confidence interval.

(4) Low temperature $\left(10^{\circ} \mathrm{C}\right)$, packed in polyethylene film $(0.03 \mathrm{~mm})$.

All samples were stored for 12 days from June 16 to 27, 1978. The packed samples were ventilated two times each day. Ten samples were pulled on the lst, 5 th, 8 th, and 12 th days of storage. DLE measurements were made on all 10 samples under the conditions of $10 \mathrm{~min}$ dark period, 5,500 Ix excitation intensity, $2 \mathrm{sec}$ excitation time, and fruit temperatures ranging from 22.8 to $28.5^{\circ} \mathrm{C}$. All 10 samples were used for hardness measurements while only 5 fruits were used for acid determinations. Fig. 8 shows the change of DLE, acidity, and hardness during storage.

(I) Storage at room temperature without packing

DLE decreased rapidly during the first 5 days of storage and became weak on the 8th day. Hardness followed a similar pattern as DLE. Acidity changed very little during the first 8 days but decreased to $3.8 \%$ by the 12 th day, and dropped to $76 \%$ of the initial value. In terms of peel color, the fruit was yellow-ripe within 5 days and showed signs of decay, named as "pitting", by the 12 th day of storage.

Some interesting observations can be made if Fig: 8 is compared to Fig. 
5. The curves are similar but there is a definite difference in ripening speed. Whereas the fruit in Fig. 5 (harvested on June 7) had a higher DLE and maintained hardness and greenish color through 5 days of storage, the fruit harvested on June 16 was already yellow-ripened and by the 5th day of storage had lost it's salability. The difference in ripening speeds was probably due to different harvest dates and different storage temperatures (Fig. 8 storage temperature was $1.5^{\circ} \mathrm{C}$ higher than the storage temperature for Fig. 5).

(2) Storage of packed fruit at room temperature

Ripening of packed fruit at room temperature progressed similarly to that described above. The fruits were yellow-ripened by the 5 th day of storage and showed signs of decay by the 8th day. DLE and hardness of the packed fruit changed the same way as that of unpacked storage. Acid content decreased remarkably according to the storage duration. It was expected that the polyethylene film would concentrate the ethylene around the fruits and promote ripening.

\section{(3) Storage of non-packed fruit at low temperature}

All factors (DLE, hardness, and acidity) indicated that storage at $10^{\circ} \mathrm{C}$ reduced the metabolic processes which caused a delay in the loss of freshness and salability. Peel color of light green or yellowish-green was retained until the 12 th day of storage. Hardness had dropped to only $50 \%$ of its initial value by the 12 th day and was greater than that of the room-temperature fruit after only 5 days of storage. Acidity dropped only $15 \%$ in 12 days.

\section{(4) Storage of packed fruit at low temperature}

From peel color alone it appeared that packing the fruit in polyethylene film maintains freshness better than the unpacked test. Otherwise, DLE, acidity, and hardness showed no significant difference compared to the unpacked fruit at low temperature.

The effect of storage and packaging on the quality factors of apricots is shown in Table 1. Comparisons are made on the mean value of the quality factors on the 12th day of storage. The results definitely indicate that low temperature storage is effective for maintaining quality for prolonged periods of time.

Table 1. Hardness, acid content and DLE intensity of Japanese apricots stored for twelve days under four storage conditions (June 27th, 1978). Values within each column followed by different alphabets a, b, c, and $\mathrm{d}$ are significantly different at the 5 percent level.

\begin{tabular}{|c|c|c|c|}
\hline Storage conditions & $\begin{array}{l}\text { Hardness } \\
\text { kef } / \mathrm{mm}\end{array}$ & $\begin{array}{l}\text { Acid content } \\
\text { Dercent }\end{array}$ & $\begin{array}{l}\text { DLE intensity } \\
\text { volt }\end{array}$ \\
\hline Room temp. & $1.36 \mathrm{a}$ & $3.79 \mathrm{a} \mathrm{d}$ & $0.092 \mathrm{a}$ \\
\hline Room temp. packed & $0.91 \mathrm{a}$ & $2.63 \mathrm{~b}$ & $0.168 \mathrm{~b}$ \\
\hline Low temp. & $4.75 \mathrm{~b}$ & $4.53 \mathrm{c} \mathrm{d}$ & $2.14 \mathrm{c}$ \\
\hline Low temp. packed & $3.88 \mathrm{c}$ & $4.74 \mathrm{c}$ & $2.03 \mathrm{c}$ \\
\hline
\end{tabular}




\section{REFERENCES}

Chuma, Y. and K. Nakaji 1970 Optical properties of fruits and vegetables to serve the automatic selection within the packing house line (4). J. Soc. Agr. Machinary, Japan, $38: 217-224$

Chuma, Y. and K. Nakaji 1980 Delayed light emission as a means of color sorting of plant products. In "Food Process Engineering, Vol. 1 Food Processing Systems", ed. by P. Linko et al., Applied Science Publishers Ltd., London, pp. 314-319

Chuma, Y., K. Nakaji and W. F. McClure 1982 Delayed light emission as a means of automatic color sorting of persimmon fruits (Part 1). DLE fundamental characteristics of persimmon fruits. J. Fac. Agr., Kyushu Univ., 27: 1-12

Iwata, T. and K. Ogata 1976 Studies on storage and chilling injury of Japanese apricot (Mume, Prunus mume Sieb. et Zucc.) fruits (I). J. Japan. Soc. Hort. Sci., 44: 422-428 